\title{
Correction to: Exploring experiences of people participation activities in a British national health service trust: a service user- led research project
}

\author{
Adrian Curwen ${ }^{1}$, Jane Fernandes ${ }^{1}$, Rachael Howison ${ }^{1}$, Paul Binfield ${ }^{1}$, Frank Rohricht ${ }^{2}$ and Domenico Giacco ${ }^{2,3,4^{*}}$
}

\section{Correction to: Res Involv Engagem (2019) 5: 5 https://doi.org/10.1186/s40900-019-0140-8}

In the publication of this article [1] there is an error in the Results section in the sub-section 'Better financial incentives and less bureaucracy'.

The error: "Some participants felt that the financial incentives to be involved were too scarce and increasing the retribution for service user involvement may be a way to get more people interested."

Should instead read: "Some participants felt that the financial incentives to be involved were too scarce and increasing the remuneration for service user involvement may be a way to get more people interested."

This has now been included in this correction.

\begin{abstract}
Author details
${ }^{1}$ East London NHS Foundation Trust, People Participation Team, London E1 8DE, UK. ${ }^{2}$ East London NHS Foundation Trust, London E1 8DE, UK. ${ }^{3}$ Unit for Social and Community Psychiatry (WHO Collaborating Centre for Mental Health Service Development), Queen Mary University of London, London E1 4NS, UK. ${ }^{4}$ Unit for Social and Community Psychiatry, Newham Centre for Mental Health, Glen Road, London E13 8SP, UK.
\end{abstract}

Received: 29 January 2019 Accepted: 29 January 2019

Published online: 28 February 2019

\section{Reference}

1. Curwen A, Fernandes J, Howison R, et al. Exploring experiences of people participation activities in a British national health service trust: a service user-led research project. Res Involv Engagem. 2019;5:5 https://doi.org/10. 1186/s40900-019-0140-8.

\footnotetext{
*Correspondence: d.giacco@gmul.ac.uk

${ }^{2}$ East London NHS Foundation Trust, London E1 8DE, UK

${ }^{3}$ Unit for Social and Community Psychiatry (WHO Collaborating Centre for

Mental Health Service Development), Queen Mary University of London,

London E1 4NS, UK

Full list of author information is available at the end of the article
}

(c) The Author(s). 2019 Open Access This article is distributed under the terms of the Creative Commons Attribution 4.0 International License (http://creativecommons.org/licenses/by/4.0/), which permits unrestricted use, distribution, and reproduction in any medium, provided you give appropriate credit to the original author(s) and the source, provide a link to the Creative Commons license, and indicate if changes were made. The Creative Commons Public Domain Dedication waiver (http://creativecommons.org/publicdomain/zero/1.0/) applies to the data made available in this article, unless otherwise stated. 